\title{
Avoiding the risk of aspiration in intubated infants
}

\author{
JOSEPH M. BRAND, DO \\ NANCY L. BRODSKY, PHD \\ HALLAM HURT, MD
}

\begin{abstract}
Aspiration is a potential problem in intubated infants who are fed enterally. In this prospective study, ${ }^{10}$ intubated preterm infants were fed orogastrically or oroduodenally. Aspiration was assessed by examining endotracheal aspirates for evidence of blue-colored dye. None of the babies had blue-colored endotracheal secretions when fed by either route. Heart and respiratory rates, blood pressure, and transcutaneous oxygen and carbon dioxide measurements were recorded at each interval of the study. There were no significant differences from baseline for these measurements. These findings indicate that there is no significant aspiration in intubated preterm infants who are fed by the orogastric or the oroduodenal route.
\end{abstract}

Achievement of adequate caloric intake in sick neonates who require assisted ventilation is difficult, and the most effective manner of feeding remains controversial. ${ }^{1-6}$ Although total parenteral nutrition can be used, its attendant complications ${ }^{7}$ have led most nurseries to initiate enteral feedings in infants who need long-term ventilator support. Some authors advocate duodenal feedings, ${ }^{6}$ whereas others recommend the gastric ${ }^{5}$ approach. In clinical practice, nasoduodenal, oroduodenal, nasogastric and orogastric methods all are used.

Aspiration is one of the hazards of feeding infants who are intubated with uncuffed endotracheal tubes, with previous studies ${ }^{8,9}$ showing an incidence of $75 \%$ to $80 \%$. Specifically, Goodwin and associates ${ }^{9}$ reported that 16 of 20 intubated premature infants had evidence of aspiration.

Concerned that our ventilator-dependent infants could be having episodes of silent aspiration, we decided to evaluate the incidence of aspiration in our own nursery. The purpose of this study was twofold: (1) to evaluate the incidence of aspiration in intubated infants by instilling a dye-colored formula directly into the stomach or duodenum; and (2) to compare the incidences of aspiration in intubated infants fed by the orogastric versus the oroduodenal route.

\section{Materials and methods}

In a prospective, crossover study, the incidence of aspiration was evaluated in 10 preterm infants (six boys, 4 girls) who were fed by both orogastric and oroduodenal routes. All infants were intubated with an uncuffed endotracheal tube, were on mechanical ventilation for longer than 72 hours, and were given enteral feedings of $100 \mathrm{cc} / \mathrm{kg} /$ day for at least 24 hours.

The mean birthweight was $889 \pm 325$ (range, 600 $\mathrm{g}$ to $1670 \mathrm{~g}$ ), and the mean gestational age was $27.5 \pm 2.5$ weeks (range, 25 weeks to 33 weeks). Mean weight and age at initiation of the study were $1203 \pm 339 \mathrm{~g}$ (range, $740 \mathrm{~g}$ to $1940 \mathrm{~g}$ ) and $35.9 \pm$ 22.3 days (range, 10 days to 74 days), respectively.

To achieve a distinguishable color, one drop of sterile Food, Drugs \& Cosmetics [Act] \# 1 blue dye was mixed with $30 \mathrm{cc}$ of infant formula. To assess the effect of dilution with gastric or duodenal contents, sterile water was mixed with the solution; color was still distinguishable at a dilution of 1:64.

All infants were placed in the 30 -degree elevated prone position while being fed to minimize any gastroesophageal reflux. ${ }^{10}$ Infants fed by the bolus and continuous feeding methods were kept in this position 2 and 3 hours, respectively. Initially, nine infants were fed dye-colored formula by the oroduodenal route, and one was fed orogastrically. After at least a 24 -hour washout period, the same infants were fed by the alternate route. Nine babies were fed by bolus and one by the continuous method through the orogastric tube; all were fed by the continuous method through the oroduodenal tube. Placement of the oroduodenal tube was verified by roentgenography.

To test for aspiration after a bolus feeding, the infant's endotracheal tube was suctioned 10, 30, 60 , and 120 minutes post-feeding. For continuous feedings, the formula was infused for at least 60 
minutes prior to obtaining aspirates at study intervals. At each interval, endotracheal secretions were collected in a separate mucous trap. Heart and respiratory rates, blood pressure, and transcutaneous oxygen and carbon dioxide measurements were recorded at each time interval.

Aspiration was assessed by examining endotracheal aspirates for evidence of blue-colored dye. The infant's nurse and a physician observed and recorded the color of the secretions at study intervals. In addition, at the end of the study, one of the investigators (JMB) reviewed all specimens for evidence of blue color.

The protocol for this study was approved by the Institutional Review Board, and informed, written parental consent was obtained prior to study in all cases. Statistical analysis included the two-tailed Student's t-test; a difference of $P<0.05$ was considered to be significant. Data are presented as the mean $\pm \mathrm{SD}$.

\section{Results}

No infant had evidence of formula aspiration; all collected secretions were clear. In addition, there were no significant differences from baseline for respiratory rate, blood pressure, and transcutaneous oxygen and carbon dioxide measurements with either orogastric or oroduodenal feeding.

\section{Discussion}

In our study, no infant had evidence of aspiration when fed oroduodenally or orogastrically. This finding is in marked contrast to that of Goodwin and associates, ${ }^{9}$ who reported aspiration in $80 \%$ of intubated preterm infants. Their high incidence of aspiration may be related to their testing method, which was instillation of a solution of Evans' blue dye directly onto the tongue rather than into the stomach. It is possible that some dye mixed with saliva and was aspirated.
Although reflux has been shown to be dependent on volume in the stomach at any given time, ${ }^{11}$ this variable was minimized, because nine of 10 infants were fed by bolus through the orogastric tube. By placing our dye-colored formula directly into the stomach or duodenum, we specifically addressed the issue of formula aspiration.

\section{Conclusion}

From our data, we conclude that the risk of aspiration of formula is low in intubated preterm infants who are fed in the 30-degree prone position via the orogastric or the oroduodenal route.

Supported in part by grant F-85-02 from Burroughs-Wellcome Osteopathic Research Fellowship and by research funds from the National Osteopathic Foundation Mead Johnson Fellowship Grant Program.

1. Beddis J, McKenzie S: Transpyloric feeding in the very low birthweight (1500 $\mathrm{g}$ and below) infant. Arch Dis Child 1979;54:213-217.

2. Benda GIM: Modes of feeding low-birth-weight infants. Semin Perinatol 1979;3:407-415.

3. Dryburgh E: Transpyloric feeding in 49 infants undergoing intensive care. Arch Dis Child 1980;55:879-882.

4. Minoli I, Moro G, Ovadia MF: Nasoduodenal feeding in high-risk newborns. Acta Pediatr Scand 1978;67:161-168.

5. Pereira GR, Lemons JA: Controlled study of transpyloric and inter mittent gavage feeding in the small preterm infant. Pediatrics 1981;67:6872.

6. VanCaillie M, Powell GK: Nasoduodenal versus nasogastric feedings in the very low birthweight infant. Pediatrics 1975;56:1065-1072.

7. Postuma R, Trevenen CL: Liver diseases in infants receiving total parenteral nutrition. Pediatrics 1979;63:110-115.

8. Browning DH, Graves SA: Incidence of aspiration with endotracheal tubes in children. $J$ Pediatr 1983;102:582-584.

9. Goodwin SR, Graves SA, and Haberkern CM: Aspiration in intubated premature infants. Pediatrics 1985;75:85-88.

10. Meyers WF, Herbst JJ: Effectiveness of positioning therapy for gastroesophageal reflux. Pediatrics 1982;69:768-772.

11. Herbst JJ: Gastroesophageal reflux. J Pediatr 1981;98:859-870.

From Albert Einstein Medical Center, Northern Division, Temple University School of Medicine, Philadelphia.

Reprint requests to Joseph Brand, DO, St. Vincent's Hospital, Perinatal Center, PO Box 13508, Green Bay, WI 54307-3508. 


\section{THE NEWLY \\ DIAGNOSED HYPERTENSIVE}

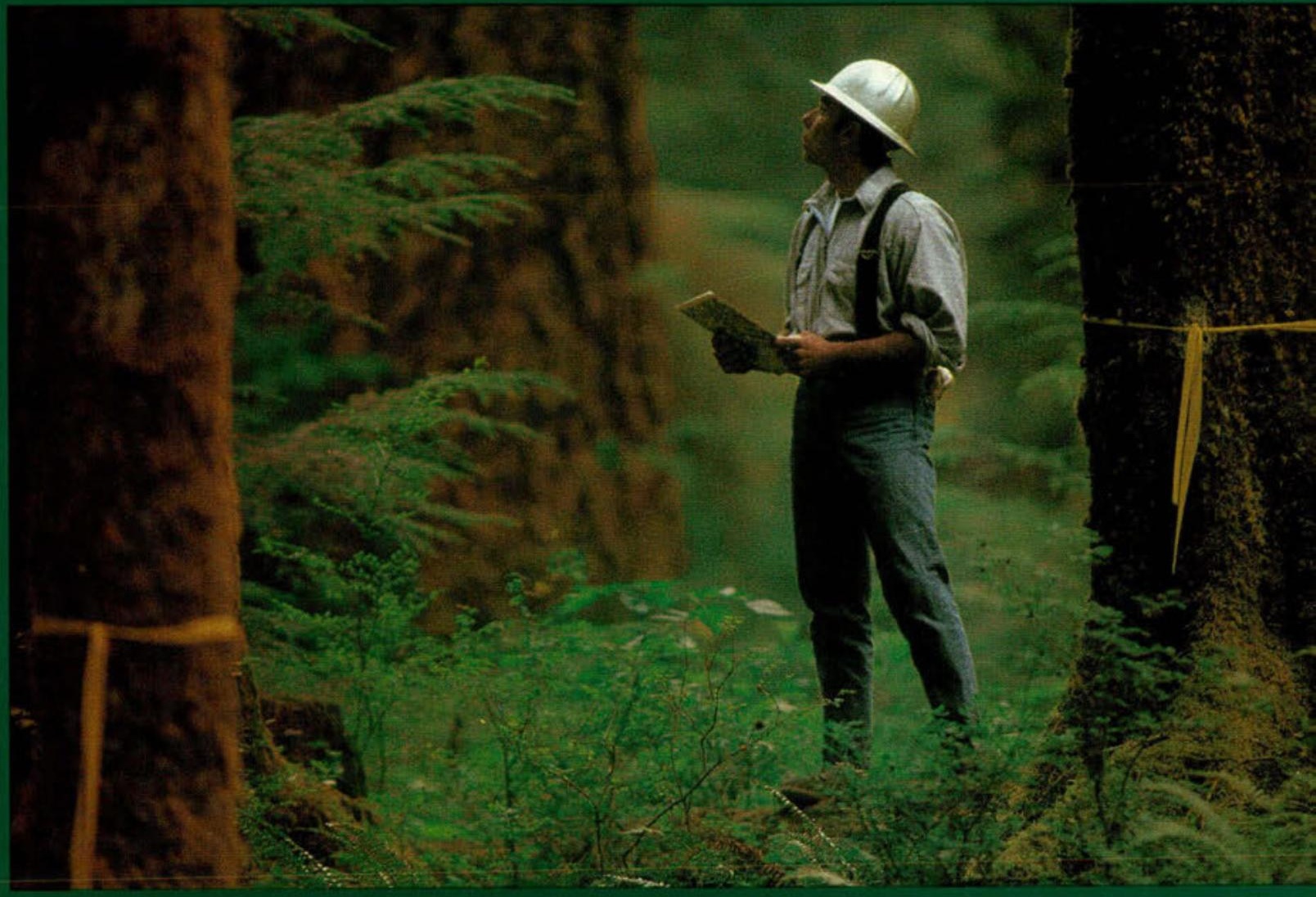

\section{THERAPY SHOULD NOT CHANGE THE WAY HE FEELS}

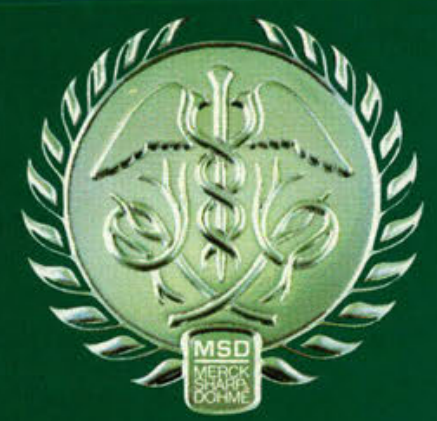




\section{LOWER HIS BLOOD PRESSURE, NOT HIS PERFORMANCE}
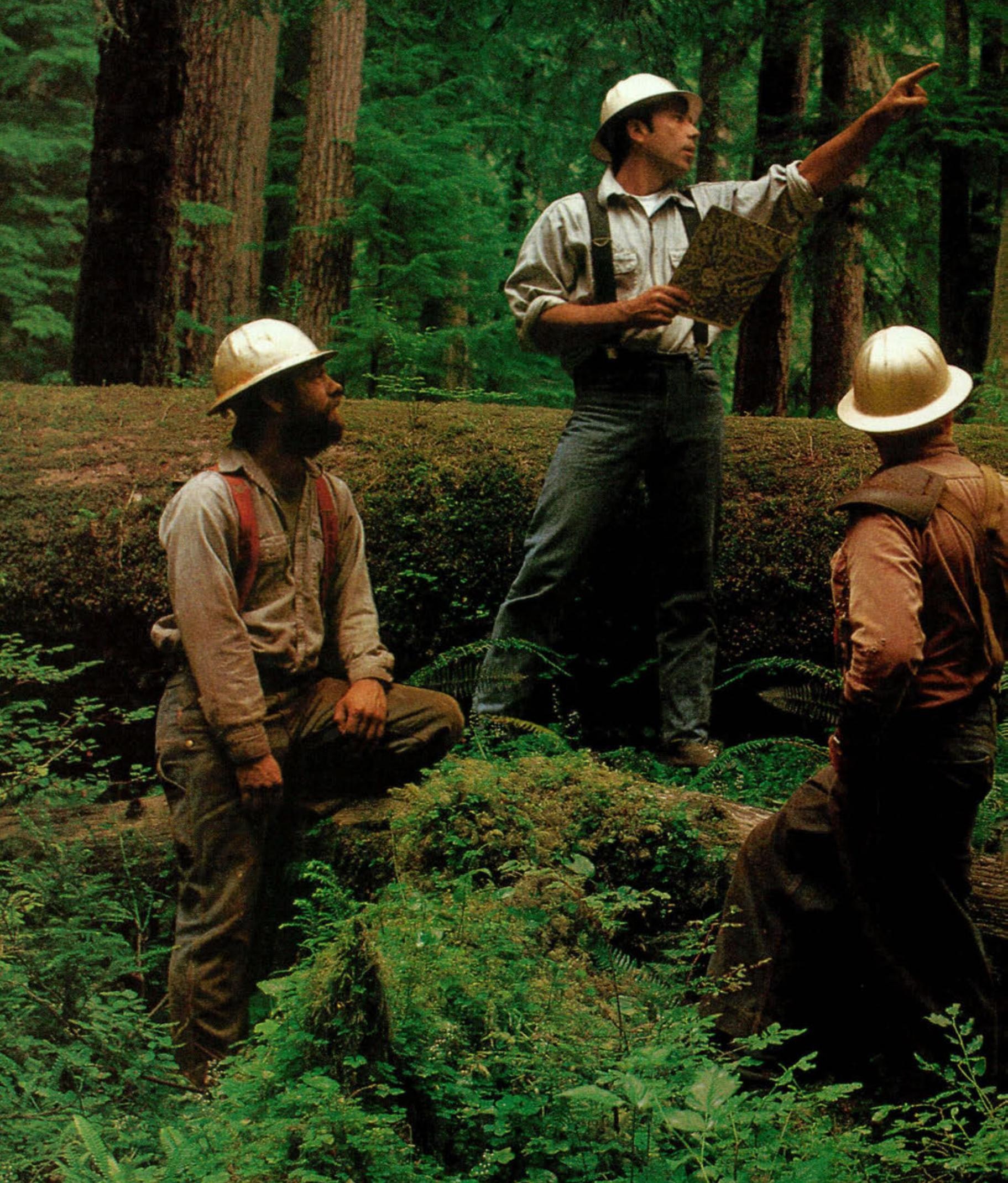


\title{
FOR MANY HYPERTENSIVE PATIENTS START WITH ONCE-A-DAY
}

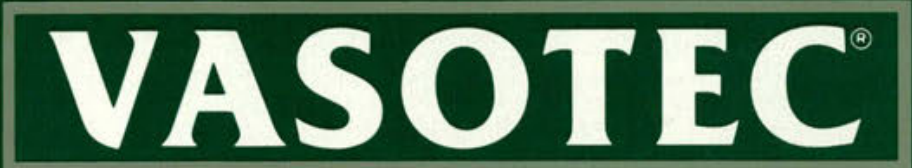

(ENALAPRIL MALEATE $\mid$ MSD)

VASOTEC is generally well tolerated and not characterized

by certain undesirable effects associated with selected

(4) agents in other antihypertensive classes. Thus, VASOTEC

is being prescribed as initial therapy for hypertension

by an increasing number of physicians.

VASOTEC generally has little or no effect on a patient's

physical or mental activity, since it is not characterized

by certain subjective symptoms (such as malaise or

drowsiness) which may interfere with such activity. This

highly favorable tolerability profile may be related to the specificity of action of VASOTEC on the renin-angiotensinaldosterone system.

\begin{abstract}
VASOTEC is contraindicated in patients who are hypersensitive to this product and in patients with a history of angioedema related to previous treatment with an ACE inhibitor.
\end{abstract}

Patients at risk for excessive hypotension, sometimes associated with oliguria and/or progressive azotemia and rarely with acute renal failure and/or death, include those with heart failure, hyponatremia, high-dose diuretic therapy, recent intensive diuresis or increase in diuretic dose, renal dialysis, or severe volume and/or salt depletion of any etiology. It may be advisable to eliminate the diuretic (except in heart failure patients), reduce the diuretic dose, or increase salt intake cautiously before initiating therapy with VASOTEC in patients at risk for excessive hypotension who are able to tolerate such adjustments. in patients at risk for excessive hypotension, therapy should be started under very close medical supervision, and such patients should be followed closely for the first two weeks of treatment and whenever the dose of enalapril and/or diuretic is increased.

In using VASOTEC, consideration should be given to the fact that another ACE inhibitor, captopril, has caused agranulocytosis, particularly in patients with renal impairment or collagen vascular disease, and the available data are insufficient to show that VASOTEC does not have a similar risk.

If angioedema of the face, extremities, lips, tongue, glottis, and/or larynx develops, VASOTEC should be promptly discontinued and the patient carefully observed until the swelling disappears. Angioedema associated with laryngeal edema may be fatal.

For more details, including information on treatment, see the Brief Summary of Prescribing Information on the last page of this advertisement. 
